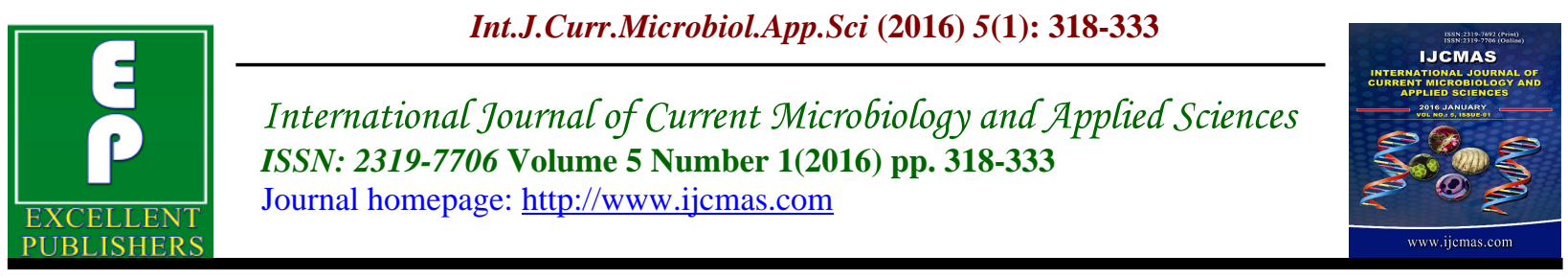

Original Research Article

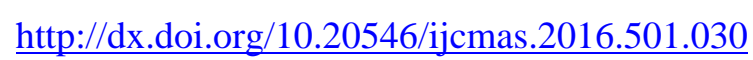

\title{
The Effect of Organic Pollution and Risk Factor along the Tripoli Harbour-North Lebanon
}

\author{
R.Salhab ${ }^{1}$, Z. Olama ${ }^{2} *$ and H. Holail ${ }^{3}$ \\ ${ }^{1}$ Department of Biological and Environmental Sciences Faculty of Science, \\ Beirut Arab University, Debbieh, Lebanon \\ ${ }^{2}$ Department of Botany and Microbiology, Faculty of Science, Alexandria University, Egypt \\ ${ }^{3}$ Azm University, Tripoli, Lebanon \\ *Corresponding author
}

\begin{abstract}
A B S T R A C T
Keywords

Tripoli Harbor, Polycyclic

Aromatic

Hydrocarbons, Solid-Phase Extraction (SPE)

Article Info

Accepted:

16 December 2015

Available Online:

10 January 2016

Lebanese marine water is exposed to the major point sources of pollution, such as sewage outfalls, industrial wastewater effluents, costal agricultural runoffs, seafront dumps, and oil spills. Data on quality of Lebanese coastal waters is highly limited. The main objectives of this study was the quantification of 16 US EPA PAHs in the sea water in" Tripoli Harbor", Lebanon one of the major harbors in the Middle East area. Twenty sea water samples were collected during January and February 20123, in accordance with the established norms and standards. Quantification using SPE and risk assessment of PAHs levels was evaluated to assess the possibility of occurrence of adverse health risk effects. Results showed that contamination with 16 US PAHs in water samples was observed all over the harbor with higher concentrations recorded at the near shore sites locations. Ratio of specific PAH compound including Phenantharene/Anthracene and Fluoranthene/Pyrene were calculated to evaluate the possible sources of PAHs contamination. These ratios reflect a petrogenic origin of PAHs in the studied water samples. The toxicity of the studied PAHs in Fish is the least compared. However, the most vulnerable and sensitive organisms in the study area are algae, followed by Daphnia.. Thus, these results necessitate the proposal of integrated intervention plans for the protection of Tripoli Harbour and that the pollution of the area must be cut back or stopped.
\end{abstract}

\section{Introduction}

Marine pollution includes a wide range of threats sources such as oil spills, untreated sewage, persistent organic pollutants and heavy metals. Lebanese marine water is exposed to the major point sources of pollution, such as sewage outfalls, industrial wastewater effluents, costal agricultural runoffs, seafront dumps, and oil spills (ElFadel \& Sadek, 2000). Data on quality of Lebanese coastal waters is highly limited. Among a wide variety of organic pollutants present in water, polycyclic aromatic hydrocarbons are of particular importance since they are widespread, persistent and 
toxic. Due to their mutagenic, and carcinogenic characteristics (Sakaria, et al., 2011), PAHs have been listed as priority pollutants by the U.S Environmental Protection Agency and the European Union. These organic compounds containing two or more fused benzene rings can induce oxidative stress and oxidative DNA damage through the metabolic activation and the generation of reactive oxygen species (Valavanidis et al., 2008). Numerous sources can impart the PAHs entry to the marine environment such as pyrogenic sources which include combustion of fossil fuels and biomass burning and petrogenic input which include unburned fossil fuels, primarily by surface runoff, accidental spills and intentional discharge by ships (Baek et al., 1991).

Tripoli Harbour (Fig. 1) which is the $2^{\text {nd }}$ largest harbor in Lebanon is considered as semi closed water body affected mainly from loading/unloading operations, municipal and agricultural wastes resulting from Tripoli city, the second largest city in Lebanon. Lebanon is a small Mediterranean country (surface area 10,452 $\mathrm{km}^{2}$, and average width $45 \mathrm{~km}$ ) located South-West Asia. The main objectives of this study is the quantification of 16 U.S EPA PAHs levels in seawater at "Tripoli Harbor in an attempt to evaluate the pollutional load. In addition, risk assessment of 16 US EPA PAHs pollution were evaluated to assess the possibility of occurrence of adverse health effect and its eco-toxicological risk assessment on the marine environment.

\section{Materials and Methods}

\section{Study Area and Sampling Procedure}

Twenty water samples were collected from different locations along the study area of Tripoli Harbor during between January and
February shown in Fig.2. Througout the sampling procedure a GPS was used to locate the sampling sites.These water samples were collected at a depth of $0.5 \mathrm{~m}$ in $2.5 \mathrm{~L}$ dark glass bottles pre-cleaned with organic solvents and pyrolyzed for 24 hours.

Water samples were preserved at $4{ }^{0} \mathrm{C}$ before

PAHs pollutants analysis.

\section{US EPA PAHs Samples Analysis}

\section{Chemical Reagents and Materials}

Dichloromethane, methanol, isooctane and ethanol of HPLC grade were obtained from Merck and Sigma-Aldrich. The 16 EPA PAHs were purchased from Restek as mix Standard Reference Solution of $1000 \mu \mathrm{g} . \mathrm{mL}^{-}$ ${ }^{1}$ in dichloromethane $(99 \%)$. The pure solid surrogate standards, naphthalene- $d_{8}$ (Nap$d_{8}$ ), phenanthrene- $d_{10}$ (Phe- $\left.d_{10}\right)$, anthracene$d_{10}$ (Ant- $\left.d_{10}\right)$, fluoranthene- $d_{10}\left(\right.$ FL- $\left.d_{10}\right)$ and chrysene- $d_{12}\left(\mathrm{Chr}-d_{12}\right)$, were purchased from Supelco with an additional deuterated PAH, pyrene- $d_{10}$ (Pyr- $\left.d_{10}\right)$, used as an internal standard. Intermediary solutions containing $25 \mu \mathrm{g} . \mathrm{mL}^{-1}$ of the 16 PAHs were prepared by diluting the standard reference solution with methanol. From the intermediary solution, PAHs working solutions at a level of 1 mg. $\mathrm{L}^{-1}$ were prepared. Separate 1000 $\mu \mathrm{g} . \mathrm{mL}^{-1}$ stock solutions of each deuterated standard were prepared by dissolving about $0.01000 \mathrm{~g}$ of the compounds in $10 \mathrm{~mL}$ of isooctane. Intermediary $25 \mu \mathrm{g} \cdot \mathrm{mL}^{-1}$ deuterated solutions of internal standard were prepared in isooctane. The working solutions of surrogate and internal deuterated standards were prepared at a concentration of $1 \mu \mathrm{g} \cdot \mathrm{mL}^{-1}$ by appropriate dilution. All standard solutions were stored in amber vials at $-20^{\circ} \mathrm{C}$. 


\section{Filtration of Seawater Samples}

$500 \mathrm{~mL}$ of samples were filtered through What-man GF/C and GF/F glass-fibre filters (1.6 and $0.7 \mu \mathrm{m}$ porosity).

\section{Solid Phase Extraction Procedure}

PAHs compounds are highly hydrophobic, the reversed-phase bonded silica sorbent $\left(\mathrm{C}_{18}\right)$ was chosen and the SPE Chromabond $\mathrm{C}_{18}$ ec polypropylene $3 \mathrm{~mL}$ cartridges packed with $200 \mathrm{mg}$ of adsorbent were purchased from Machery-Nagel, Germany. The SPE cartridges were pre-conditioned and activated at the beginning with $3 \mathrm{~mL}$ of dichloromethane loaded on the cartridge, followed by $3 \mathrm{~mL}$ of methanol and finally 3 $\mathrm{ml}$ of water.Each water sample was percolated using a regulated vacuum through the SPE cartridge with a flow rate of $5-10 \mathrm{~mL} / \mathrm{min}$. The cartridge was left to dry by applying vacuum for about 1 hour (Marce \& Borrul, 2000). The analytes were eluted by percolating $3 \mathrm{~mL}$ of dichloromethane 3 times on the SPE cartridge at atmospheric pressure. The dichloromethane was collected in a collection tube placed beneath the cartridge. Extract was concentrated to $100 \mu \mathrm{L}$ under a weak stream of nitrogen at $51{ }^{\circ} \mathrm{C}$ using a sample concentrator from Techne, USA. The obtained extract was reconstituted in $200 \mu \mathrm{L}$ of isooctane and stored in the dark at

about $-20^{\circ} \mathrm{C}$ until measurement.

\section{GC-MS Instrumentation and Conditions}

GC Agilent 7890A with a multi-mode inlet (MMI), PTV and split/split less injectors, was used for the analysis of the target PAHs. The GC was coupled to an Agilent 5975C single quadrupole mass spectrometer operated in electron ionization (EI) mode at $70 \mathrm{eV}$. Injection was carried out using an Agilent 7693A auto sampler system. ChemStation was the data processor. A single taper glass wool liner with a volume of $900 \mu \mathrm{L}$, was purchased from Agilent. The separation was achieved with an HP-5MS Ultra Inert fused silica capillary column (30 $\mathrm{m} \times 0.25 \mathrm{~mm}$ internal diameter, $0.25 \mu \mathrm{m}$ film thickness) from Agilent Technologies. The GC oven initial temperature program was 40 ${ }^{\circ} \mathrm{C}$ (hold $2 \mathrm{~min}$ ), increased to $200{ }^{\circ} \mathrm{C}$ at 15 ${ }^{\circ} \mathrm{C} / \mathrm{min}$ (hold $2 \mathrm{~min}$ ), and finally increased to $280{ }^{\circ} \mathrm{C}$ at $5{ }^{\circ} \mathrm{C} / \mathrm{min}$ (hold $5 \mathrm{~min}$ ). The total run time was about $35 \mathrm{~min}$. Helium (purity > 99.999\%) was used as carrier gas at $1.5 \mathrm{~mL} \cdot \mathrm{min}^{-1}$ flow rate. Transfer line temperature and ion source temperature were maintained at $280{ }^{\circ} \mathrm{C}$ and $250{ }^{\circ} \mathrm{C}$, respectively. The injection volume was 5 $\mu \mathrm{L}$, and all injections were in programmed temperature vaporization PTV mode with an injection speed of $32 \mu \mathrm{L} \cdot \mathrm{min}^{-1}$. A temperature of $50^{\circ} \mathrm{C}$ with a split flow of 100 $\mathrm{mL} . \mathrm{min}^{-1}$ for $0.16 \mathrm{~min}$ under a pressure of 15 psi were the conditions chosen for the solvent vent. The analytes purge was accomplished in splitless mode with a flow of $60 \mathrm{~mL} \cdot \mathrm{min}^{-1}$ for $3 \mathrm{~min}$ at a temperature of $280^{\circ} \mathrm{C}$. The analyses were performed in SIM mode using two or three ions for each compound to increase sensitivity and high realibility of identification (Table1). Confirmation criteria for the detection of PAHs should include the following: (a) retention time for two monitored ions for a given analyte should maximize simultaneously $\pm 0.1 \mathrm{~s}$; (b) the ratio between the two monitored ions should be within $15 \%$ of the theoretical value. Quantitation was performed by internal standard calibration using a six-point regression line ranging from 1 to $500 \mathrm{ng} \cdot \mathrm{mL}^{-1}$.

\section{Quality Assurance}

Blank: The sum of the analyzed PAHs was 
evaluated in a high quality Lebanese drinking water and its low value was considered to be negligible, so it was used as a blank during the experiments. Blank water samples were included at a rate of one for every five samples and were treated in exactly the same manner as the samples during the SPE process to monitor the contamination. In addition, during the GCMS analysis each water sample was followed by a blank solvent injection to prevent cross contamination and interferences between samples.

\section{Recovery experiments}

Spiked water samples were prepared by adding a native PAH solution to blank water samples at a concentration of $50 \mathrm{ng} \cdot \mathrm{L}^{-1}$. Spiked water samples were extracted using SPE and analyzed by GC/MS exactly like the seawater samples. Recoveries of the analyzed PAHs were evaluated in order to check the efficiency of the analytical process.

\section{Surrogate and Internal Deuterated standards}

Four surrogate standards (Phe- $\mathrm{d}_{10}$, Ant- $\mathrm{d}_{10}$, FL-d ${ }_{10}$ and Chr- $\mathrm{d}_{12}$ ) were added to seawater samples at a fixed concentration of 100 ng. $\mathrm{L}^{-1}$ prior to extraction in order to monitor the entire analytical process from sample preparation to instrument performance. Recovery of each surrogate standard was evaluated and used to correct the losses of the corresponding PAHs. The internal standard (pyrene- $\mathrm{d}_{10}$ ) was added to all samples just before GC-MS analysis with a fixed amount of 50ng.

\section{Eco-Toxicological Risk Assessment Index}

Toxic units for each organism and sample (TUT) were calculated using a simple additive approach as the sum of the individual PAHs toxic units (TU), which correspond to the ratio between the concentrations of the individual PAH and its critical toxicological end point for the test organism $\left(\mathrm{EC}_{50}\right)$ shown in Table 2, according to the following equations

$\mathbf{T U}_{P}=\left[\mathrm{PAH}\right.$ conc/end point $\left(\mathbf{E C}_{50}\right.$, $\left.\mathbf{L C}_{50 . .)}\right]_{P} \quad \mathbf{T U}_{T}=\sum \mathbf{T U}_{P}$

Were $\mathrm{P}$ is the PAH and "end point" is relative to each aquatic organism, as presented in Table 4 for Algae, Daphnia and Fish. The short-term PAH Risk Index (PRISW-1 index) was originally developed for individual chemicals like pesticides but it has also been applied to PAHs. A procedure for assesing the risk posed to the aquatic ecosystems by persticide mixtures has been proposed by Finizio et al. (2001). This index is based on, first, the calculation of TERs (Toxicological Exposure Ratios) for each samples and the three non target orgqanisms such as Algae, Daphnia and Fish as the ration between the critical toxicological "end point" (EC50 for Algae, Daphnia and Fish) and the predicted environmental concentration (PEC), which in the present study was substituted for the real PAH concentrations measured in the samples, and, second, the application of the following equation that assigns to each TER a score and a weight related to the type of organism:

\section{PRISW-1 $=(A \times 3)+(B \times 4)+(C \times 5.5)$}

where A, B, C are the scores assigned to the TERs for Algae, Daphnia and Fish, respectively, and 3,4 and 5.5 are the corresponding weights. The scores (for all three organisms) are assigned as follows: 0 for TERs > 10000, 1 for TERs in the range $10,000-1,000,2$ for TERs in the range 1000-100, 4 for TERs in the range 100-10, 6 for TERs in the range 10-2, and 8 for TERs < 2. As it can be deduced from the 
explanations above the TERs are the reciprocal of the corresponding TUs (i.e. TER $=1 /$ TUT $)$.

Finally, the environmental risks caused by the PAH present in the samples are classified, according to the resulting PRISW-1 values, into negligible (PRISW$1 \leq 5)$, low $(5<$ PRISW- $1 \leq 15)$, medium $(15$ $<$ PRISW-1 $\leq 40)$, high $(40<$ PRISW-1 $\leq$ 80 ), and very high (PRISW-1 > 80).

\section{Statistical Design}

Quantitative variables were described in terms of frequencies, mean, standard deviation, min and max. Paired sample t-test was used for testing the difference between the physical parameters between June and November. The Type-1 error $\alpha$ was set at $5 \%$. Pearson Correlation coefficients were used to evaluate correlations between variables and was performed between physico-chemical parameters microbiological counts and PAHs. The analyses and values were subjected to linear regression analysis for the determination of $\mathrm{R}$ using SPSS17 (Kutner et al., 2004). The correlation coefficient was used to indicate the relation of two random variables.

\section{Results and Discussion}

\section{Evaluation of the Analytical Procedure}

\section{Recoveries of PAHs}

Recovery is the best indicator of the efficiency of the analytical procedure. According to the US Environmental Protection Agency methods guidelines, good recovery values should be in the range from 70 up to $120 \%$, however, values between 50 $\%$ and $140 \%$ are acceptable when analyzing some compounds like PAHs. In the present study, recoveries for individual PAH studied in water sample were in the range of 62104\% except for the 3 low molecular weight PAHs, Nap, AcP and AcPy (recoveries < $50 \%$ ) shown in Table 3. These 3 compounds, with very high volatility, were lost during manipulation and therefore were not considered in the quantitative analysis.

Surrogate Standards Evaluation

Results presented in Fig. 3 indicated average recovery of $64-90 \%$ for the deuterated PAHs used as surrogate standards. The lowest recovery was for $\mathrm{Chr}-\mathrm{d}_{12}$ about $61 \%$. The highest recovery was for Phe- $\mathrm{d}_{10}$ about $90 \%$ followed by Ant- $\mathrm{d}_{10}$ and FL-d $\mathrm{d}_{10}$ with about $71 \%$ recovery. The concentration of each targeted PAH was corrected according to the recovery of its corresponding surrogate. This correction resulted in an increase in the total amount of the 13 PAHs in water sample up to $64 \%$.

\section{PAHs Levels and Spatial Distribution}

Results of the study provide information about the contamination of surface seawater with PAHs, which are considered as one of the most dangerous group of environmental pollutants because of their relatively high concentration level, diverse sources, and toxicity to aquatic organisms. The PAHs distribution among these sites differs substantially from site to site, reflecting the complexity in $\mathrm{PAH}$ source.Concentrations of $\sum$ PAHs in water samples ranged from 0.5 $\mathrm{ngL}^{-1}$ to $727.77 \mathrm{ngL}^{-1}$. The maximum concentration of PAHs was observed at sites 4 and 16, a location affected by intensive shipping activities and sewage disposal. Contamination with PAHs in the water samples was observed all over the port with higher concentrations recorded in the near shore stations shown in the map of Fig. 4 were the red color indicates the highest concentrations of $\sum$ PAHs while the orange and yellow indicates intermediate pollution. 
However the green to blue color indicates slight concentrations of $\sum$ PAHs.

PAHs concentrations were generally lower in the port area under construction where there are no shipping activities. It was also noted that the deep water samples contained less amounts of PAH then those near shore. It was observed that the total PAH levels at the near shore sites was higher than the maximum admissible concentrations of the European Union of $200 \mathrm{ngL}^{-1}$ and the Environmental Quality Criteria of the United States, $\Sigma$ PAHs $=30 \mathrm{ngL}^{-1}$ for protection of human consumers of aquatic life (EPA, 2009) whereas all the other sites were below the levels. In addition, sites 4, 5 and 16 had higher concentration of $\sum \mathrm{PAH}$ than those of the EPA National Recommended Water Quality Criteria for the protection of aquatic life.. In terms of the concentrations of individual $\mathrm{PAH}$ compounds it was revealed that the concentration varied considerably within the samples. Seven of the compounds analyzed were detected at all the sampling sites. Such a wide range of PAHs at different concentrations indicates that there are potentially many different sources of PAHs in the area, possibly including combustion followed by oil residues, sewage outfalls, and industrial wastewater.

Individual PAHs content varies considerably within the water samples. PAH compounds were grouped into 3 groups according to their number of aromatic rings and analysed. The Low molecular weight compounds PAHs, fluorene and phenanthrene represented a significant portion of the tested PAHs concentrations in Tripoli Harbor. Flourene ranged from $0.20 \mathrm{ngL}^{-1}$ to 166.2 $\mathrm{ngL}^{-1}$ and phenancrene ranged from 2.20 $\mathrm{ngL}^{-1}$ to $370.7 \mathrm{ngL}^{-1}$. However Anthracene was present at a lower concentration compared to fluorene and phenanthrene, it ranged between 0.30 to $32.7 \mathrm{ng} / \mathrm{L}$. Medium molecular weight PAHs were present and at some sites were not detected especially Benzo[b] fluoranthene and Benzo[k] fluoranthene that were detected on site 1 only. In addition, Benzo[ $a]$ pyrene, was not detected at all sites with the exception of sites 3, 4, 5 and 23 where it was detected but not quantified. On the other hand, fluranthene, pyrene, chrysene, and Benzo $[a]$ anthracene were present at most sites except sites 10, 11, 12. Fluoranthene was reported to range from $1.20 \mathrm{ng} / \mathrm{L}$ to 47.2 $\mathrm{ngL}^{-1}$. Pyrene on the other hand ranged from 1.10 to $100.3 \mathrm{ngL}^{-1}$. However, chrysene levels were somehow similar on all sites with an average of $1.2 \mathrm{ngL}^{-1}$ but with the exception of site 4 which had the highest pollutional load of chrysene $\left(12.3 \mathrm{ngL}^{-1}\right)$. In addition Benzo[ $a]$ anthracene had similar low values at most sites except site 4 (27.1 $\left.n g L^{-1}\right)$.

The high molecular weight $\mathrm{PAH}$, were not detected at some sites while other sites were detected but not quantified because of their high hydrophobicity, and low solubility.

Comparing the date in the present study with data obtained from different studies done in other areas of the world (Table 4): it was found that total PAH concentrations found in Tripoli harbor water is about 10 folds greater than Chesapeake Bay $(20$ - 65.7 $\left.\mathrm{nL}^{-1}\right)$. On the other hand, the Baltic Sea, Saronikos Gulf, Deep Bay, South China and Western Taiwan Strait reported slightly less values than the values of $\sum$ PAHs obtained in the present study. However, Daya Bay, China and Mumbai Harbor in India had very high concentrations of PAHs which was much higher than the results in the present study.

\section{Source of PAHs and Diagnostic Interpretation}


Sources of PAHs in waters can either be of pyrogenic origins or petrogenic input. Anthropogenic PAHs mainly come from combustion of fossil fuels and spillage of petroleum. The sources PAHs, whether from pyrolytic or petrogenic contamination, may be identified by ratios of individual $\mathrm{PAH}$ compounds based on peculiarities in $\mathrm{PAH}$ composition and distribution pattern as a function of the emission source. PAHs from petrogenic source are characterized by the predominance of the low molecular weight PAHs, while pyrogenic sources are characterized with higher abundance of high molecular weight PAHs. Diagnostic interpretation of the distribution of certain PAHs in sea water such as Phe/Ant and Flu/Pyr ratios have been used to distinguish the possible petrogenic or pryogenic sources (Manoli \& Samara, 1999). Petroleum often contains more phenanthrene relative to anthracene, which is more thermodynamically stable tricyclic aromatic isomer, so that the Phe/Ant ration is observed to be very high in case of petrogenic pollution with PAHs but low in pyrogenic contamination case (Budzinski et al., 1997). Samples with Phe/Ant $>10.0$ and FL/Pyr $<1.0$ were mainly contaminated by petrogenic inputs whereas Phe/Ant $<10.0$ and FL/Pyr $>1.0$ were mainly contaminated by pyrogenic inputs. It was found that more than $80 \%$ of the water samples have petrogenic origin of PAHs which is a result of the direct input from petroleum and its products. Results in Fig. 5 showed that the majority of the analyzed samples were contaminated from a petrogenic source.

\section{Ecotoxicological Risk Assessment}

The PAH distribution profile indicated potential source dependence, as the levels were generally higher in the harbor line, which were higher than most studies.Their presence in marine water combined with other potentially toxic compounds can result in negative effects.

The toxicity of hydrocarbons is the result of the uptake of dissolved hydrocarbons by aquatic organisms, and it can lead to a wide variety of physiological responses. The overall picture is often complex because a range of processes, such as biodegradation, bioaccumulation, and biotransformation, will determine the bioavailability and toxic potency of PAHs and other petroleumrelated compounds in the field. Moreover, marine organisms, may vary greatly in their sensitivity to the same compound (Van der Oost et al., 2003). During the past few decades, a large body of research has been published on the biological effects and impact of petroleum-related hydrocarbons, such as PAHs, in the marine environment. PAHs with higher molecular weight are less water-soluble than two- or three-ring PAHs and tend to be bound to particles or dissolved organic compounds, resulting in lower degradability and consequently higher potential bioaccumulation in food webs or sedimentation. Chronic exposure to petroleum hydrocarbons can affect feeding, growth, and reproduction and cause irreversible tissue damage. Marine organisms such as filter-feeding molluscs have an outstanding ability to bioaccumulate hydrocarbons in their tissues, whereas other organisms, particularly vertebrates, readily metabolize and excrete them. However, the degradation pathways may create reactive intermediates with toxic effects (Van Brummelen et al., 1998). Several studies have demonstrated that PAH exposure in polluted environments results in reproductive and developmental effects in fish (Patel et al., 2006). In particular, their mutagenic and carcinogenic potential, in addition to their cytotoxic properties (Vethaak et al., 1996) pose serious threats to marine organisms, especially during 
embryogenesis and early stages of development (Incardona et al., 2005). Apart from directly affecting the reproductive status and the growth of aquatic biota, PAHs

Table.1 The Quantification, Confirmation Ions And Retention Time For Each Analyte, The Corresponding Surrogate Standard And Internal Standard

\begin{tabular}{cccc}
\hline Compound & Ouantification & Confirmation & Retention time \\
\hline Pyr- $d_{10}$ & 212 & 211 & 17.26 \\
Nap- $d_{8}$ & 136 & 137 & 8.15 \\
Nap & 128 & 129 & 8.18 \\
AcPy & 152 & 151 & 10.70 \\
AcP & 154 & 153 & 10.99 \\
Flu & 166 & 165 & 11.80 \\
Phe- $d_{10}$ & 188 & 189 & 13.35 \\
Phe & 178 & 176 & 13.38 \\
Ant- $d_{10}$ & 188 & 189 & 13.43 \\
Ant & 178 & 176 & 1328 \\
FL- $d_{10}$ & 212 & 213 & 16.58 \\
FI & $2 n 7$ & $2 n n$ & 16 \\
Pyr & 202 & 200 & 17.31 \\
Chr- $d_{12}$ & 240 & 236 & 22.13 \\
B $a \mathrm{~A}$ & 228 & 226 & 22.10 \\
Chr & 228 & 226 & 22.38 \\
$\mathrm{~B} b \mathrm{FL}$ & 252 & 250 & 26.51 \\
$\mathrm{~B} k \mathrm{FL}$ & 252 & 250 & 26.65 \\
$\mathrm{~B} a \mathrm{P}$ & 252 & 250 & 27.72 \\
$\mathrm{InP}$ & 276 & 277 & 31.77 \\
$\mathrm{nRA}$ & 278 & 276 & 37.14 \\
$\mathrm{~B} g h i \mathrm{P}$ & 276 & 277 & 32.80 \\
& & &
\end{tabular}

Table.2 Half Maximal Effective Concentration (EC-50) Of Each Organism For PAH

\begin{tabular}{cccc}
\hline \hline \multirow{2}{*}{ PAHs (mg/L) } & Algae (EC50-3 d)* & $\begin{array}{c}\text { Daphnia (EC50-48 } \\
\text { h)* }\end{array}$ & Fish (LC-50)** \\
\hline Fluorene & 0.053 & 0.72 & 1.2 \\
Phenanthrene & 0.062 & 0.84 & 1.4 \\
Anthracene & 0.013 & 0.18 & 0.03 \\
Fluoranthene & 0.075 & 0.192 & 6.8 \\
Pyrene & 0.052 & 0.132 & 1 \\
Benzo[a]anthracene & 0.01 & 0.14 & 0.014 \\
Chrysene & 0.007 & 0.06 & 0.9 \\
\hline *Eom et al., 2007 & & \\
$* *$ Ministry of the Environment in Japan (March 2013) & \\
\hline \hline
\end{tabular}


Table.3 Recovery \% of each PAH at the End of GC-MS

\begin{tabular}{c|ccc}
\hline \hline PAHs & Added (ng/L) & Found (ng/L) & Recovery \% \\
\hline Nap & 100 & 22.72 & 22.72 \\
AcPy & 100 & 20.38 & 20.38 \\
AcP & 100 & 28.31 & 28.31 \\
Flu & 100 & 68.78 & 68.78 \\
Phe & 100 & 89.24 & 89.24 \\
Ant & 100 & 96.96 & 96.96 \\
FL & 100 & 101.09 & 101.09 \\
Pyr & 100 & 100.19 & 100.19 \\
Chr & 100 & 104.00 & 104.00 \\
BaA & 100 & 98.00 & 98.00 \\
BbFL+BkFL & 100 & 84.00 & 84.00 \\
BaP & 100 & 76.00 & 76.00 \\
InP & 100 & 66.00 & 66.00 \\
DBA & 100 & 69.00 & 69.00 \\
BghiP & 100 & 62.00 & 62.00 \\
\hline \hline
\end{tabular}

Table.4 Comparison of Total PAH Concentrations (ngL-1) in Sub-Surface Water from Various Marine Sites Around the World

\begin{tabular}{ccccc}
\hline \hline Location & $\begin{array}{c}\text { Year of } \\
\text { Samnling }\end{array}$ & $\boldsymbol{N}$ & Range & References \\
\hline Chesapeake Bay, USA & 1995 & 17 & $20-65.7$ & Gustafson \& Dickhut, \\
Baltic Sea & 1995 & 14 & $300-594$ & Maldonado et al., 1999 \\
Alexandria coast, Egypt & - & - & $13-120$ & El Nemr \& Abd-Allah, \\
Daya Bay, China & 1999 & 16 & $4228-29320$ & Zhou \& Maskaoui., 2003 \\
Saronikos Gulf (Greece) & - & 17 & $425-459$ & Valavanidis et al., 2008 \\
Deep Bay, South China & 2004 & 15 & $24.7-690$ & Qiu et al., 2009 \\
Western Taiwan Strait, China & 2009 & - & $12.3-580$ & Wu et al., 2011 \\
Mumbai Harbour Line, India & 2008 & 15 & $8660-46740$ & Dhananjayan et al, 2012 \\
Tripoli Harbour, Lebanon & 2013 & 20 & $0.5-727.7$ & Present study \\
\hline \hline
\end{tabular}


Table.5 Toxic Unit Value, Short-Term PAH Risk Index and Environmental Risk of each Site

\begin{tabular}{cccccc}
\hline \hline $\begin{array}{c}\text { Site } \\
\text { Number }\end{array}$ & \multicolumn{3}{c}{ TU } & PRISW-1 & $\begin{array}{c}\text { Environmental } \\
\text { risks }\end{array}$ \\
\cline { 2 - 4 } & Algae & Daphnia & Fish & & High \\
2 & 1.04 & 0.14 & $2 \times 10^{-4}$ & 53.5 & High \\
3 & 1.68 & 0.24 & $3 \times 10^{-4}$ & 53.5 & High \\
4 & 1.23 & 0.24 & $2 \times 10^{-4}$ & 53.5 & High \\
5 & 17.78 & 2.05 & $3.3 \times 10^{-3}$ & 67 & Medium \\
8 & 5.23 & 0.61 & $7 \times 10^{-4}$ & 34 & Medium \\
10 & 0.35 & 0.04 & $7 \times 10^{-5}$ & 34 & Medium \\
11 & 0.01 & 0.01 & $1.3 \times 10^{-5}$ & 25.5 & Medium \\
12 & 0.08 & 0.01 & $1.5 \times 10^{-5}$ & 20 & Medium \\
16 & 0.03 & 0.01 & $1 \times 10^{-5}$ & 20 & High \\
20 & 12.47 & 1.65 & 0.002 & 67 & High \\
23 & 0.51 & 0.04 & $7 \times 10^{-5}$ & 40 & High \\
25 & 0.77 & 0.09 & $1.9 \times 10^{-4}$ & 53.5 & Medium \\
26 & 0.479 & 0.06 & $7.9 \times 10^{-5}$ & 34 & Medium \\
28 & 0.22 & 0.03 & $4.9 \times 10^{-5}$ & 39.5 & Medium \\
29 & 0.305 & 0.04 & $4.9 \times 10^{-5}$ & 34 & Medium \\
30 & 0.41 & 0.04 & $6.7 \times 10^{-5}$ & 34 & Medium \\
31 & 0.35 & 0.04 & $6.5 \times 10^{-5}$ & 34 & Medium \\
33 & 0.22 & 0.03 & $3.7 \times 10^{-5}$ & 34 & High \\
44 & 3.05 & 0.04 & $5.3 \times 10^{-5}$ & 40 & Medium \\
\hline \hline
\end{tabular}

Table.6 Correlation Relation of $\sum \mathrm{PAH}$ with Physico-chemical and Microbiological Parameters

\begin{tabular}{cc|c}
\hline \hline \multicolumn{2}{c|}{ Correlation } & $\sum$ PAH \\
\hline \multirow{2}{*}{$\sum$ PAH } & P. Correlation & 1 \\
& Sig. (2-tailed) & $-0.717^{* *}$ \\
\multirow{2}{*}{ Temperature } & P. Correlation & 0.000 \\
& Sig. (2-tailed) & $-0.448^{*}$ \\
& P. Correlation & 0.048 \\
\hline \multirow{2}{*}{ pH } & Sig. (2-tailed) & $-0.870^{* *}$ \\
& P. Correlation & 0.000 \\
\hline \multirow{2}{*}{ D.O (mg/L) } & Sig. (2-tailed) & -0.224 \\
& P. Correlation & 0.343 \\
\hline \multirow{2}{*}{ E.C (mS/cm) } & Sig. (2-tailed) & -0.208 \\
& P. Correlation & 0.380 \\
\hline \multirow{2}{*}{ TDS (ppm) } & Sig. (2-tailed) & $0.755^{* *}$ \\
& P. Correlation & 0.000 \\
\multirow{2}{*}{ Total Coliform } & Sig. (2-tailed) & $0.524^{*}$ \\
& P. Correlation & 0.018 \\
\hline \multirow{2}{*}{ Fecal Coliform } & Sig. (2-tailed) & *. Correlation is significant at the 0.01 level (2-tailed) \\
\multirow{2}{*}{$*$. Correlation is significant at the 0.05 level (2-tailed) } \\
\hline \hline
\end{tabular}


Fig.1 Structures of the 16 U.S EPA PAHs

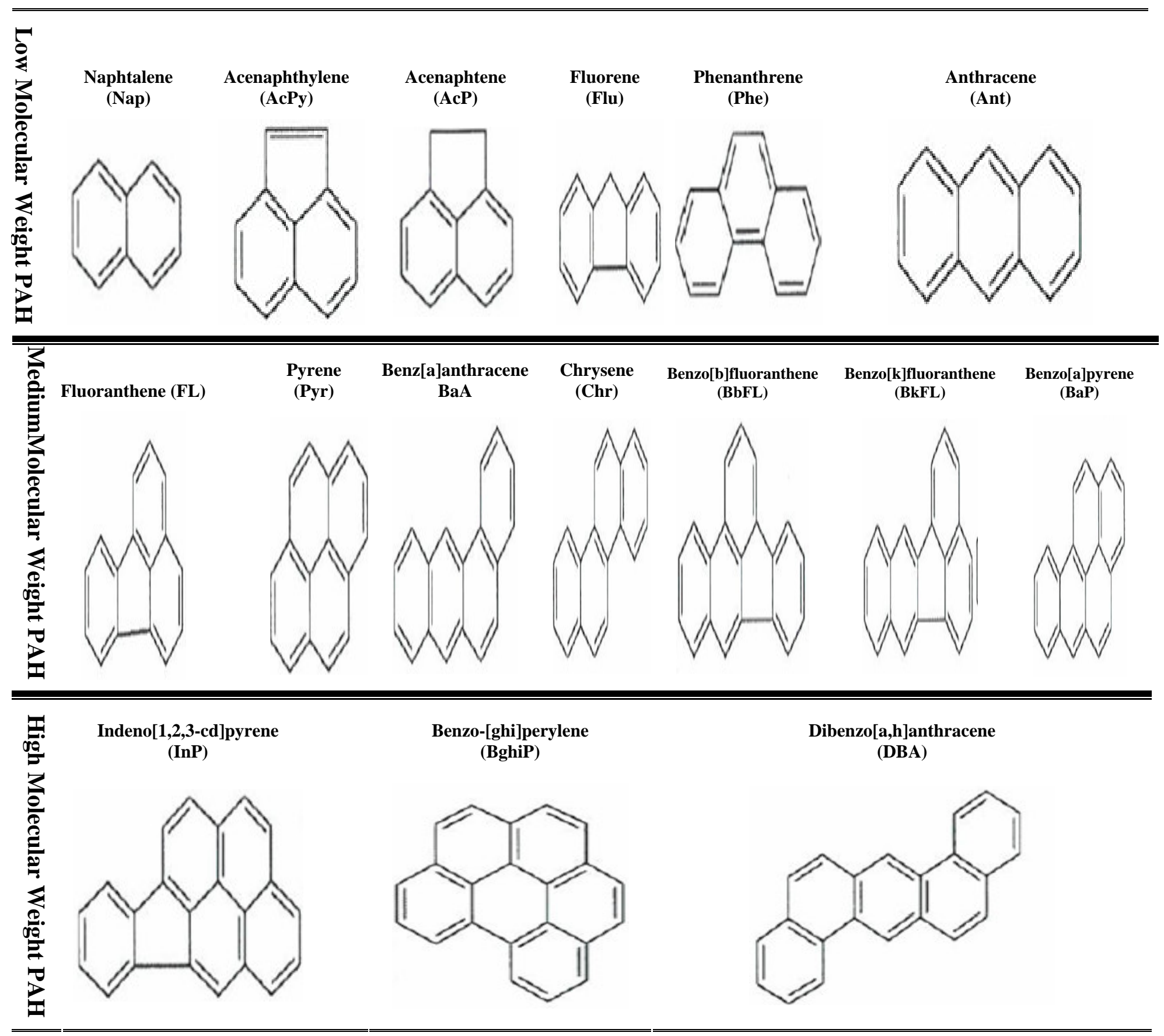


Fig.2 Geographical Location of the Study Area Showing Sampling Sitess for the 16 US EPA PAHs

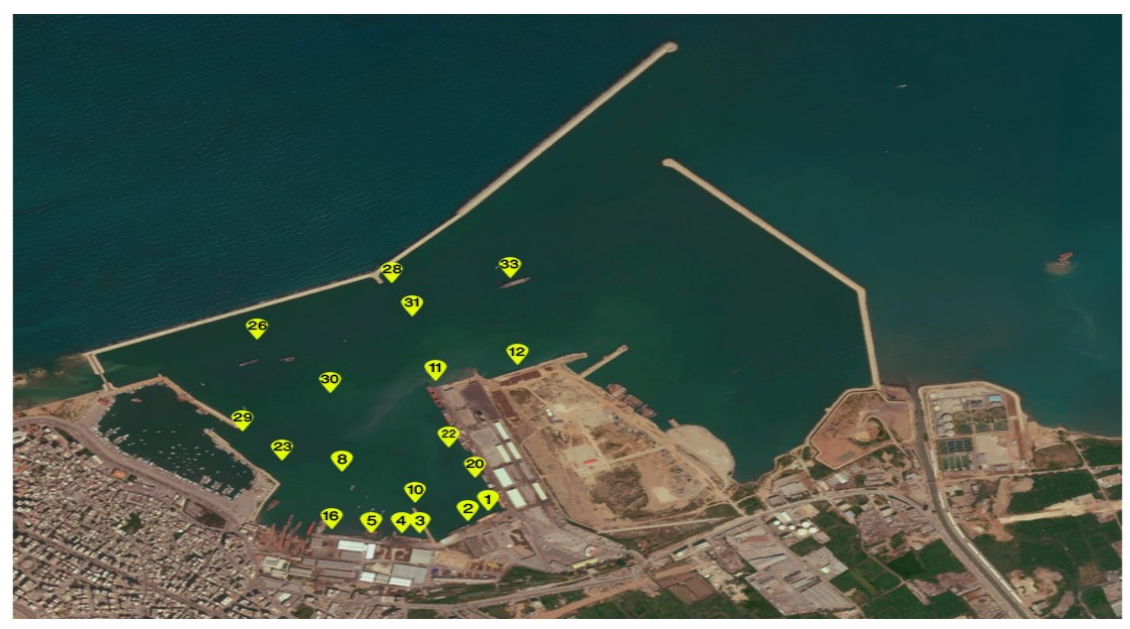

Fig.3 Average Recovery of Surrogates in Water Samples

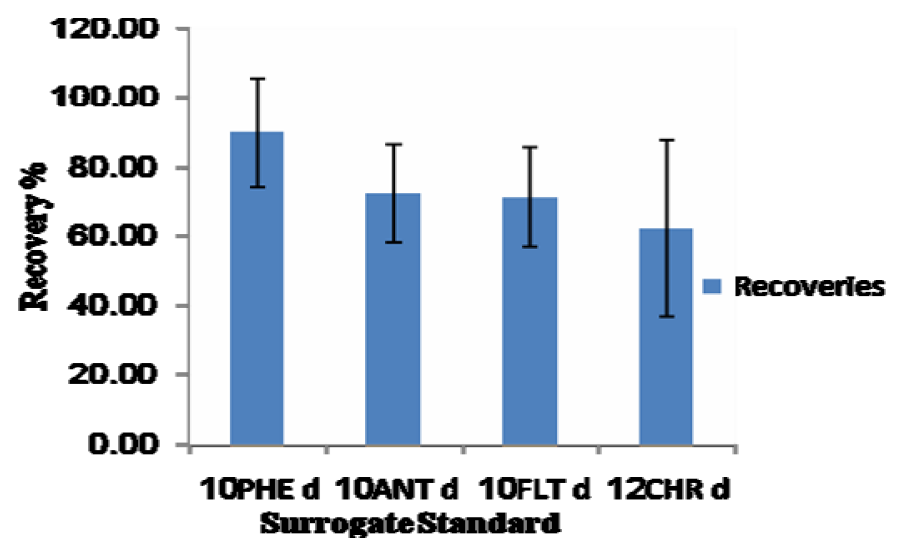

Fig.4 Spatial Concentration and Distribution of the $\sum$ PAH (ngL-1) in Water Samples of Tripoli Harbor

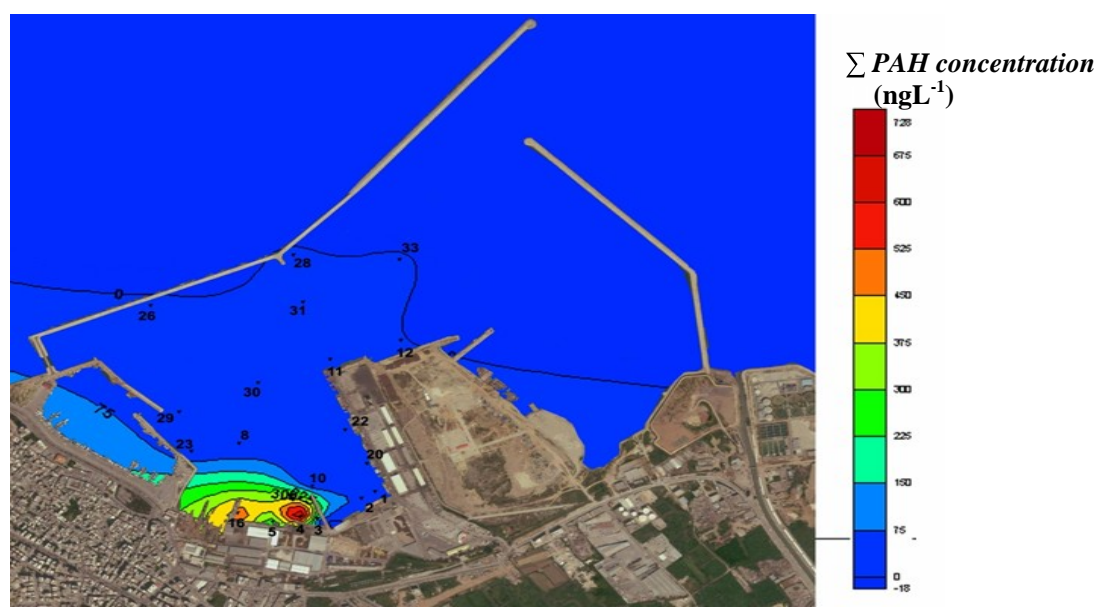


Fig.5 PHE/ANT Versus FLT/PYR Plots of PAHs in Water Samples

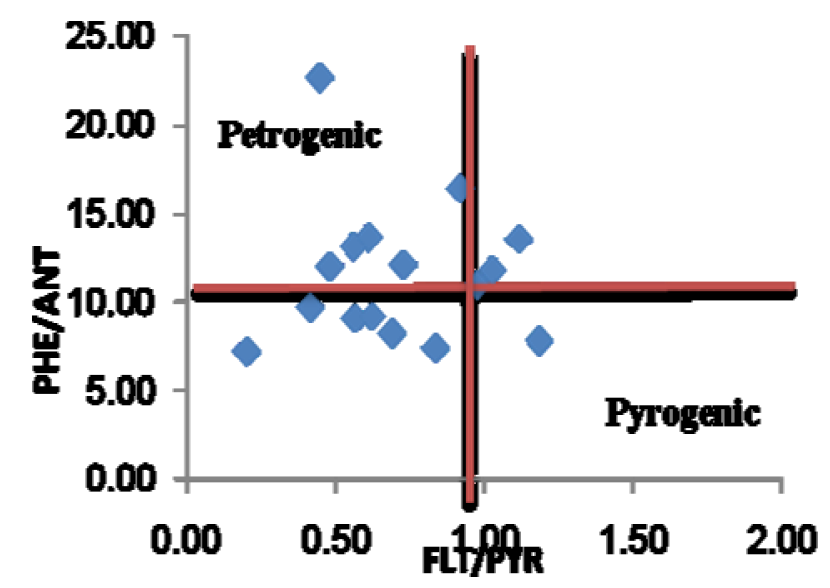

Fig.6 Toxic Unit of Three Representative Aquatic Organisms in the Studied Sample Sites

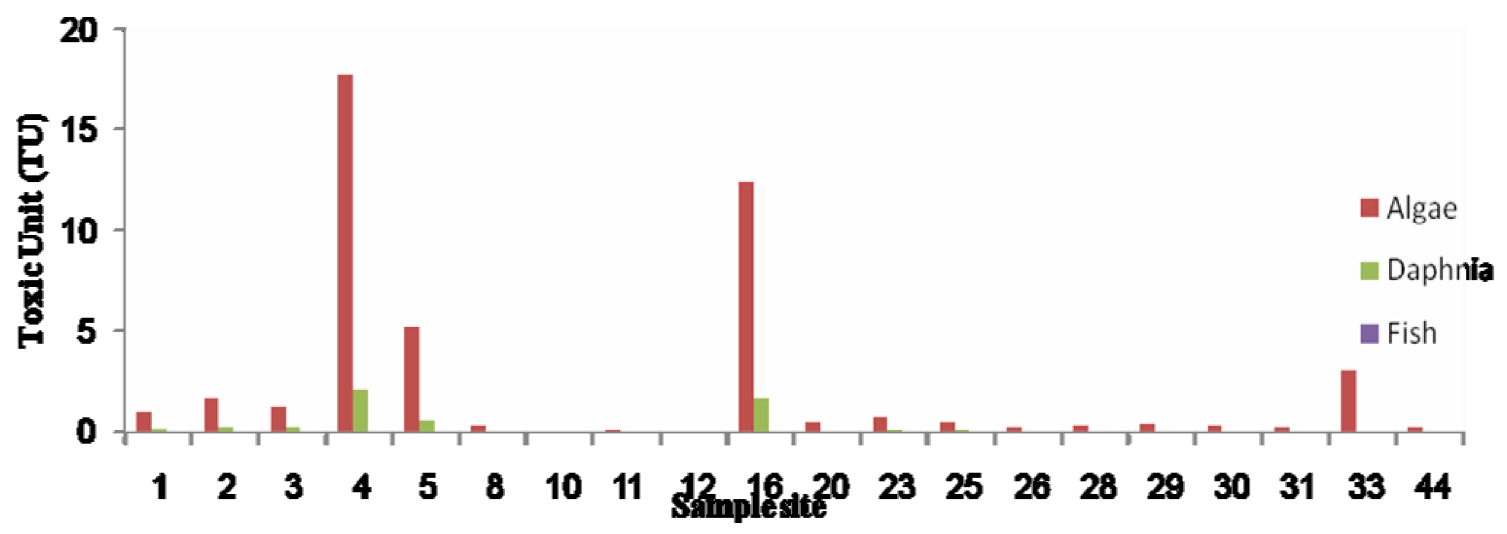

These alterations can reach higher levels of biological organization, where they may alter vital functions that affect the survival of organisms and cause damage in populations and communities (Peterson et al., 2001).As a result, to assess the real effect of PAH on aquatic life, both concentrations and harmful effects on aquatic organisms must be jointly considered. In addition, it was revealed that also PAHs present at low concentrations have high toxicity and they can be more relevant than more concentrated ones. Since PAH have low vapor pressures and octanolwater partition coefficient ( $\log$ Kow $>3$ ), therefore, they are rapidly absorbed by particulate matter and by living organisms and are classified as having high potential for bioaccumulation (Nielsen et al., 1997).

In the present study, the toxic unit for each sample and organism (Algae, Daphnia and Fish) were calculated from the concentrations of the PAHs measured in the samples and their toxicity (EC-50) towards the corresponding organisms. Their relative contribution to the overall sample toxicity (sum of the TUs calculated for the three organisms). In all samples, the analyzed toxicity in Fish is the least compared to that calculated for algae and Daphnia. In addition, it was noted that the most vulnerable and sensitive organisms in the study area are algae, with TUs between 0.01 to 17.78. On the other hand, Daphnia recorded TUs between 0.01 to 2.05 , while 
the toxic unit for fish ranged is very low with values less than 0.002 shown in table and figure 6.

Samples 4, 5 and 16 show clearly a very toxic effect on algae. It is also noted that the most affected organisms in all the sampling areas are algae, followed by daphnia. On the other hand, the samples, which are characterized by having lower PAH concentrations along the study area, also have effects on both algae and crustacean. The Short-term PAH Risk Index for the Surface Water System (PRISW-1) for each sample considering the PAH toxicity against three representative aquatic organisms is shown in Table 5 and it was noted that the environmental risk was medium at $60 \%$ of the sites. However, all the other sites reported high environmental risks.

\section{Correlation Relation of $\sum$ PAH with Physico-Chemical Variables and Microbial Population}

Correlation matrix showed a negative correlation of different rates between physicochemical parameters and $\sum \mathrm{PAH}$ meaning that they are moving in opposite directions with varying degrees. The correlation between $\sum \mathrm{PAH}$ and temperature and between $\sum$ PAH and DO showed a strong negative correlation with $r=-0.717$ $(\mathrm{p}<0.001 ; \mathrm{p} \leq 0.05)$ value and $-0.870(\mathrm{p}<$ $0.001 ; \mathrm{p} \leq 0.05) \quad$ respectively. These results are similar to the findings stated by Bauer \& Capone, (1985) who reported that $\sum$ PAH degrade most rapidly at elevated temperatures and at elevated oxygen levels. The correlation between $\sum \mathrm{PAH}$ and $\mathrm{pH}$ is an intermediate negative one with $\mathrm{r}=$ $0.448(p=0.048 ; p \leq 0.05)$. However, the correlation between $\sum \mathrm{PAH}$ and EC is nonsignificant with $\mathrm{r}=-0.224(\mathrm{p}=0.343)$. Similarly, the correlation between $\sum \mathrm{PAH}$ and TDS was non-significant weak with a value of $r=-0.208(p=0.380)$.
On the other hand, correlation relation between $\sum$ PAH and total and fecal coliforms was significantly correlated with an $\mathrm{r}$ value of $0.755(\mathrm{p}<0.001 ; \mathrm{p} \leq 0.05)$ and $0.524(\mathrm{p}=$ $0.018 ; \mathrm{p} \leq 0.05)$ respectively meaning that they are varying in the same direction. These results comply with the findings of Lay \& Zsolnay, (1989) who stated that the introduction of sewage can lead to a local increase in the amount of organic material.

The results of this study indicated that there is a clear threat to the Lebanese coast and the Mediterranean Sea from land-based sources of pollution. The PAH distribution profile indicated potential source dependence, as the levels were generally higher in the harbor line and were higher than most studies which proves the urgent need to establish a monitoring program for PAHs in water to ensure that any excess in concentrations over environmental quality standards is rapidly reported and necessary actions are taken. Their presence in marine water combined with other potentially toxic compounds can result in negative effects. The leakage of oils, oily wastes and mixtures can directly cause damage to fishery resources, aquatic biota and coastal habitat. These effects may seriously damage marine and coastal ecology. Fishery resources, including shellfish, may be spoiled by oil and toxic substances generated by biodegradation. It is widely acknowledged that the pollution of the sea must be cut back or stopped by issuing laws on possible effluents and prevention of future emission of pollutants.

\section{References}

El-Fadel, M,; Sadek, S. (2000). Wastewater Management along Mediterranean Coast: A Treatment Application Decision Case Study, Journal of Natural Resources and Life Sciences Education. 29:116-124. 
Sakaria, M., et al., (2011). The History of Petroleum Pollution in Malaysia; Urgent Need for Integrated Prevention Approach.

Valavanidis, A.; Vlachogianni, T.; Triantafillaki, S.; Dassenakis, M., Androutsos, F. and M. Scoullos.( 2008). Polycyclic Aromatic Hydrocarbons in Surface Seawater and in Indigenous Mussels (Mytilus Galloprovincialis) from Coastal Areas of the Saronikos Gulf (Greece), Estuarine, Coastal And Shelf Science. 79(4): 733-739.

Baek, S.; Field, A. and Goldstone, E. (1991). Water Air Soil Poll, 60: 279300.

Marce, R. and Borrul, F. (2000). Solid-phase extraction of Polycyclic Aromatic Compounds. J. Chromatography A. 885: 273-290.

Finizio, A.; Calliera, M. and Vighi, M. (2001). Rating Systems for Pesticide Risk Classification on Different Ecosystems. Ecotogicol. Environ. Saf. 49:262-274.

Eom, I.; Rast, C.; Veber, A. and Vasseur, P. (2007). Ecotoxicity of a polycyclic aromatic hydrocarbon(PAH)contaminated soil. Ecotoxicology and Environmental Safety 67:190-205.

Kunter, M.; Nachtshein, C. and Neter, J. (2004). Applied Linear Regression Models. $4^{\text {th }}$ Ed. Boston, 25.

Environmental Protection Agency, EPA. (2009). Aquatic Life Ambient Freshwater Quality Criteria - Copper: 2007 Revision. Office of Water. EPA822 R-07-001.

Gustafson, K. and Dickhut, R. (1997). Distribution Of Polycyclic Aromatic Hydrocarbons In Southern Chesapeake Bay Surface Water: Evaluation Of Three Methods For Determining Freely Dissolved Water Concentrations, Environmental Toxicology And Chemistry. 16: 452-461.
Dhananjayan, V.; Muralidharan, S. and Peter, R. (2012). Occurrence and Distribution of Polycyclic Aromatic Hydrocarbons in Water and Sediment Collected along the Harbor Line, Mumbai, India. International Journal of Oceanography. 1-7.

Maldonado, C.; Bayona, J. and Bodineau, L. (1999). Sources, Distribution, and Water Column Processes of Aliphatic and Polycyclic Aromatic Hydrocarbons in The Northwestern Black Sea Water. Environmental Science and Technology. 33(16):2693-2702.

El Nemr, A. and Abd-Allah, A. (2003). Contamination of Polycyclic Aromatic Hydrocarbons in Micro Layer And Subsurface Waters Along Alexandria Coast, Egypt, Chemo-Sphere. 52:17111716.

Zhou, J. and Maskaoui, K. (2003). Distribution of polycyclic Aromatic Hydrocarbons in Water and Surface Sediments from Daya Bay, China, Environmental Pollution. 121: 269-281

Valavanidis, A.; Vlachogianni, T.; Triantafillaki, S.; Dassenakis, M., Androutsos, F. and M. Scoullos.( 2008). Polycyclic Aromatic Hydrocarbons in Surface Seawater and in Indigenous Mussels (Mytilus Galloprovincialis) from Coastal Areas of the Saronikos Gulf (Greece), Estuarine, Coastal And Shelf Science. 79(4): 733-739.

Qiu, Y.; Zhang, G.; Liu, G.; Guo, L.; Li, X. and Wai, O. (2009). Polycyclic Aromatic Hydrocarbons (Pahs) in the Water Column and Sediment Core of Deep Bay, South China, Estuarine, Coastal and Shelf Science. 83(1):6066.

Wu, L.; Wang, N.; Li, Y. and Hong, Y. (2011). Occurrence of Polycyclic Aromatic Hydrocarbons in Seawater from the Western Taiwan Strait, China, Marine Pollution Bulletin. 63:5-12. 
Manoli, E. and Samara, C. (1999). Polycyclic Aromatic Hydrocarbons in Natural Waters: Sources, Occurrence and Analysis. Trends, Anal. Chem. 18:417- 428.

Budzinski, H.; Jones, I.; Bellocq, J.; Pierard, C. and Garrigues, P. (1997). Evaluation of Sediment Contamination by Polycyclic Aromatic Hydrocarbons in the Gironde Estuary, Marine Chemistry. 58:85-97.

Van der Oost, R.; Beyer, J. and Vermeulen, N. (2003). Fish Bioaccumulations and Biomarkers in Environmental Risk Assessment: A Review. Environmental Toxicology and Pharmacology. 13:57-149.

Van Brummelen, T.; Van Hattum, B.; Crommentuijn, T. and Kalf, D. (1998). Bioavailability and Ecotoxicity of PAHs. The Handbook of Environmental Chemistry, 3: 412.

Patel, M.; Scheffler, B.; Wang, L. and Willet, K. (2006). Effects of Benzo(A)Pyrene Exposure on Killifish (Fundulus Heteroclitus) Aromatase Activities And Mrna. Aquatic Toxicology. 10:267-278.

Vethaak, A.; Jol, J.; Eggens, M.; Meijboom, A.; Rheinallt, T.; Van de Zande, T.; Bergman, A.; Dankers, N.; Ariese, F.; Baan, R.; Everts, J.; Opperhuizen, A. and Marquenie, J. (1996). Skin and Liver Diseases Induced in Flounder (Platichthysflesus) after Long-Term
Exposure to Contaminated Sediments in Large-Scale Mesocosms. Environmental Health Perspectives. 11: 1218-1229.

Incardona, J.; Teraoka, H. and Scholz, N. (2005). Aryl Hydrocarbon ReceptorIndependent Toxicity of Weathered Crude Oil During Fish Development. Environmental Health Perspectives. 12:1755-1762.

Wootton, E.; Dyrynda, E.; $\quad$ Pipe, R. and Raccliffe, N. (2003). Comparisons of PAH-Induced Immuno-Modulation in Three Bivalve Molluscs. Aquatic Toxicology. 65:13-25.

Peterson, C.; McDonald, L.; Green, H. and Erickson, W. (2001). Sampling Design Begets Conclusions: The Statistical Basis For Detection Of Injury To And Recovery Of Shoreline Communities After The "Exxon Valdez" Oil Spill. Marine Ecology Progress. 210:255-283.

Nielsen, T.; Siigur, K.; Helweg, C.; Jorgensen, O.; Hansen, P.; and Kirso, U. (1997). Sorption of Polycyclic Aromatic Compounds to Humic Acid as Studied By High Performance Liquid Chromatography. Environ. Sci. Technol. 31;102-1108.

Lay, J. and Zsolnay, A. (1989). Effects in Marine Ecosystems. Ecotoxicology and Climate.195- 21

\section{How to cite this article:}

R.Salhab, Z. Olama and H. Holail. 2016. The Effect of Organic Pollution and Risk Factor along the Tripoli Harbour-North Lebanon. Int.J.Curr.Microbiol.App.Sci. 5(1): 318-333

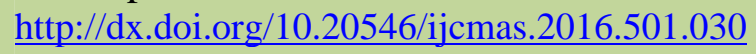

